\title{
Updates in palliative care - recent advancements in the pharmacological management of symptoms
}

\author{
Authors: Angela Star ${ }^{A}$ and Jason W Boland ${ }^{B}$
}

Symptom management is an important part of both palliative care and end-of-life care. This article will examine the recent research evidence about drugs commonly used for symptom management in adult patients receiving palliative care. In particular, the management of symptoms where recent palliative care-based evidence has changed recommended practice will be reviewed. This includes: breathlessness, delirium, nausea and vomiting in bowel obstruction, opioidinduced constipation and upper respiratory tract secretions. For each symptom, a review of recent pharmacological evidence has been undertaken, with emphasis on potential important changes to physicians' practice.

KEYWORDS: Palliative care, symptom management, breathlessness, delirium, malignant bowel obstruction

\section{Introduction}

Patients receiving palliative care can have many different symptoms. This article will highlight the recent research evidence on drugs commonly used for symptom management in patients receiving palliative care. Many of these drugs are also used in other settings. We have discussed the symptoms where recent palliative care-based evidence has changed recommended practice:

\footnotetext{
breathlessness

delirium

$>$ nausea and vomiting in bowel obstruction

opioid-induced constipation

upper respiratory tract secretions.
}

The recent evidence for pain is outside the scope of this article and will be reviewed separately in this issue.

Symptom management starts with a thorough assessment of a patient's symptoms, with the aim of finding a cause, assessing reversibility and the impact on the patient and their family. Reversible causes of symptoms should be acted upon where appropriate and an explanation to the patient and family is an essential part of management.

Authors: ${ }^{\text {A }}$ specialist registrar in palliative medicine, Sheffield Teaching Hospitals, Sheffield, UK; ${ }^{B}$ senior clinical lecturer and honorary consultant in palliative medicine, Wolfson Palliative Care Research Centre, Hull York Medical School, University of Hull, Hull, UK.
Symptoms are multidimensional experiences and will vary with underlying pathophysiology and the individual. Although this review addresses updates in pharmacological management of key symptoms, effective non-pharmacological treatments should always be considered concurrently (and often before drug therapy) as these often have fewer side effects.

\section{Breathlessness}

Breathlessness is most common in people with advanced cancer or cardiorespiratory or neurological disease. In this cohort, breathlessness generally occurs due to a mismatch between the patient's perceived need to breathe (respiratory drive) and their ability to do so (physiological capacity). ${ }^{2}$ Standard treatment includes optimising the underlying disease, reversing any reversible factors where possible, and using non-pharmacological measures (such as breathing training, exercise or use of a handheld fan). ${ }^{3}$ Recent evidence for pharmacological management of breathlessness covers oxygen, opioids and benzodiazepines.

\section{Oxygen}

Oxygen is commonly used as a long-term therapy for patients with chronic obstructive pulmonary disease (COPD) and other chronic lung diseases to reduce the risk of cor pulmonale. As such, longterm oxygen is generally considered a treatment for hypoxaemia in patients who meet specific arterial blood gas-based criteria rather than for breathlessness alone. ${ }^{4}$

A Cochrane review reported improvement of breathlessness with oxygen over medical air during exercise for patients with COPD and normoxaemia/mild hypoxaemia. ${ }^{5}$ The same review found no evidence that oxygen improved breathlessness in everyday living or that it improved quality of life among these patients. $^{5}$

Oxygen can, however, be used for symptomatically hypoxic patients with advanced illness. British Thoracic Society (BTS) guidelines recommend a trial of 'palliative oxygen' to treat breathlessness in hypoxaemic patients with cancer or end-stage cardiorespiratory disease (oxygen saturation levels $\leq 92 \%$ on air; no arterial blood gas necessary). ${ }^{6}$ Regular use of oxygen in all patients entering the last days of life (regardless of symptomatology) did not prove beneficial in a recent all-comers trial $^{7}$ and this practice is not advised.

Practice point: Consider a trial of oxygen in patients who meet BTS criteria or in symptomatically breathless patients with advanced illness and oxygen saturation levels $\leq 92 \%$ on air. 


\section{Opioids}

Systemic opioids are frequently used in low doses to palliate breathlessness. ${ }^{8}$ They have been shown not to increase mortality when used in advanced COPD at doses equivalent to $\leq 30 \mathrm{mg}$ oral morphine equivalent/day. ${ }^{9}$

There are many proposed mechanisms for the action of opioids on breathlessness, via their $\mu$-opioid receptor activity. Central processing modulation of breathlessness (similar to modulation of pain) and binding to peripheral opioid receptors within bronchioles and alveolar walls both occur. ${ }^{10}$ Recent neuroimaging research suggests opioids may also alter conditioned anticipatory brain responses to breathlessness. ${ }^{11}$

Opioids decrease the brainstem's response to hypoxia and hypercapnia. ${ }^{10}$ Although this likely decreases higher cortical awareness of dyspnoea (through 'corollary discharge'), ${ }^{12}$ physicians sometimes fear this may also lead to respiratory depression. Lowdose opioids have, however, been shown to be safe even in very severe $\operatorname{COPD}^{9}$ and no cases of respiratory depression were reported in studies using low-dose ( $\leq 30 \mathrm{mg}$ oral morphine equivalent/day) sustained release opioids for treatment of refractory breathlessness. ${ }^{3}$

A 2016 Cochrane review with meta-analysis concluded there was a low-level evidence of benefit in low-dose systemic opioids for palliation of breathlessness (decreasing breathlessness by an average of 0.28 points on a $0-10$ patient rating scale). ${ }^{10}$ Subsequently, Ekstrom et al performed a re-analysis to statistically adjust for matched data within the many crossover trials ( $92 \%$ of trials). The authors concluded that evidence supporting low-dose systemic opioids is moderate, and that they decrease breathlessness overall by an average of 0.8 points on a $0-10$ scale. $^{13}$

> Practice point: Low-dose oral or parenteral opioids ( $\leq 30 \mathrm{mg}$ oral morphine equivalent/day) are considered effective in the palliation of breathlessness, and have been shown to be safe even in severe COPD.

\section{Benzodiazepines}

Benzodiazepines are used to palliate breathlessness, especially in people with concomitant anxiety. These are commonly sublingual lorazepam, or midazolam via subcutaneous injection/infusion for patients at end of life. ${ }^{8}$ Benzodiazepines have both anxiolytic and sedative properties, ${ }^{14}$ so care must be taken to balance symptom relief with any drowsiness or sedation. Their side effects can also include physical or mental impairment and dizziness, ${ }^{14}$ raising concern for increased risk of falls in ambulatory patients.

A Cochrane review with meta-analysis analysed eight studies comparing benzodiazepines with placebo, morphine or promethazine in patients with COPD or advanced cancer. The authors did not find any evidence for or against the effectiveness of benzodiazepines (in any formulation) in treating breathlessness. ${ }^{15}$ Benzodiazepines caused more side effects than placebo (especially drowsiness or somnolence), but fewer than opioids. ${ }^{15}$ A subsequent review of non-opioid therapies in chronic breathlessness also found insufficient evidence to support benzodiazepine use. ${ }^{16}$ Benzodiazepines thus cannot be recommended for routine use in treating breathlessness, but can be considered as second- or third-line treatment when symptoms are refractory to other management including opioids. ${ }^{15}$

> Practice point: Benzodiazepines could be trialled on an individual basis to palliate refractory breathlessness, especially in patients already taking opioids and when anxiety is worsening breathlessness.

\section{Delirium}

Delirium occurs in $13-88 \%$ of palliative care inpatients (with the lowest prevalence on admission to a palliative care inpatient unit and the highest in people in the last days of life). ${ }^{17}$ Between $30-50 \%$ of delirious episodes are precipitated by potentially reversible causes including infection, faecal or urinary retention, electrolyte imbalances and medications (toxicity or withdrawal). ${ }^{18}$ These reversible causes should be sought, reversed if appropriate, and non-pharmacological treatments optimised. ${ }^{19}$

Traditional clinical management of symptomatic hyperactive delirium has included both antipsychotics and benzodiazepines (especially in severe cases where the patient is a risk to themselves or others).

\section{Antipsychotic drug therapy}

The most frequently recommended antipsychotic in palliative care is haloperidol (a first-generation butyrophenone antipsychotic drug), followed by the newer alternatives of risperidone, olanzapine, and quetiapine (second-generation antipsychotic drugs). ${ }^{20}$ For patients receiving palliative care, dose escalation, antipsychotic agent rotation, or the use of multiple antipsychotic agents may be needed to manage symptoms of delirium. $^{20}$

A recent adequately powered, double-blind, parallel-arm, randomised controlled trial compared haloperidol, risperidone and placebo for symptomatic delirium amongst 247 inpatients receiving palliative care. ${ }^{21}$ Non-pharmacological supportive measures were provided to all participants. At study end, both the haloperidol and risperidone arms had more symptomatic delirium, when compared to the placebo arm. Patients in both treatment arms experienced more extrapyramidal side effects, and those receiving haloperidol had a worse survival than the placebo group. Most patients in this trial had mild or moderate delirium, and thus might not be representative of those most likely to receive pharmacological treatment for their delirium. Antipsychotic doses were titrated to an age-adjusted maximum, which was below doses sometimes recommended in clinical practice. ${ }^{8}$ The authors emphasise caution with antipsychotic agents used in the treatment of symptomatic delirium. ${ }^{21}$

> Practice point: Always aim to find and treat any reversible causes of delirium. There is no high-quality evidence to support antipsychotic drug use in treating symptomatic delirium in palliative care. Antipsychotics should thus be reserved for severe and distressing symptomatic delirium. Non-pharmacological measures to reorient delirious patients and engage families should be used.

\section{Nausea and vomiting in malignant bowel obstruction}

Malignant bowel obstruction occurs in 3-15\% in patients with cancer; this is higher in patients with ovarian (20-50\%) and colon cancer (10-29\%). ${ }^{22}$ It can be due to mechanical obstruction by tumour (from within the gut lumen or outside the bowel wall), functional obstruction due to infiltration of the myenteric plexus or 
gut musculature, or a combination of both. Constipation, abdominal pain (continuous and colic), distension, nausea and vomiting often result. Patients with functional pathophysiological mechanisms are more likely to de-obstruct with medical treatment. ${ }^{23}$

Surgical intervention to remove a single-level obstruction should be considered, but has high postoperative morbidity, mortality, and re-obstruction rate. ${ }^{22}$ In patients with proximal obstruction who are fit for endoscopy, endoscopic stenting or venting percutaneous gastrostomy tube insertions can be less invasive alternatives to surgery. ${ }^{24}$ Although a venting gastrostomy does not restore oral digestive transit, it can successfully decompress the small bowel, reducing nausea/vomiting and improving quality of life. ${ }^{25}$

Supportive medical care is essential in patients for whom surgical and endoscopic treatments are considered unsuitable. Parenteral fluids should be considered and may even help reduce nausea and drowsiness. $^{26}$

In patients who have no colic, a prokinetic (eg metoclopramide) is recommended, to help relieve a partial or functional obstruction. ${ }^{8}$ If this causes colic or is not effective despite therapeutic dose, it should be stopped.

Management for malignant bowel obstruction-related nausea and vomiting includes centrally-acting antiemetics such as haloperidol, as well as antispasmodic and antisecretory agents (eg hyoscine butylbromide and glycopyrronium). To this, corticosteroids, ${ }^{24}$ proton pump inhibitors and/or histamine-2 antagonist drugs (eg ranitidine) ${ }^{27}$ are frequently added. Somatostatin analogues (eg octreotide) are another alternative and some consider them the first-line antisecretory treatment in malignant bowel obstruction. ${ }^{24,28}$

\section{Somatastatin analogues}

A systematic review examined the effectiveness of somatostatin analogues (including octreotide and lanreotide), when compared with either placebo or hyoscine butylbromide. Although the authors concluded there was some low level evidence of benefit in using somatostatin analogues, they noted that outcome measures varied widely and supporting evidence was predominantly from smaller trials with higher risk of bias. ${ }^{29}$ Furthermore, the two higher quality, well-powered trials with low risk of bias found no statistically significant benefit for their primary outcome measures (number of days free of vomiting at 72 hours, and response to treatment on day seven). ${ }^{30,31}$

One issue raised with the Currow et al trial is that their endpoint was 72 hours, which was thought by some proponents of octreotide to be too short to demonstrate effect. ${ }^{32}$ By contrast, Mystakidou et al noted early benefit with octreotide, but this was not maintained past 72 hours. ${ }^{33}$ This lack of lasting effect may be due to expected disease progression.

Despite the lack of evidenced benefit, octreotide (with antiemetic) is currently recommended as first-line treatment in the 2016 Multinational Association for Supportive Care in Cancer (MASCC) consensus recommendations for treating malignant bowel obstruction. $^{24}$

Practice point: There are no high-quality trials supporting the use of octreotide in the management of malignant bowel obstruction. Despite this, if octreotide is used for treating this condition it should be done on an individual case-by-case basis, with regular assessment/reassessment of efficacy and side effects.

\section{Opioid-induced constipation}

Constipation is a common side effect of opioid use. It is due to activation of opioid receptor within the gastrointestinal tract. Opioids act on circular muscle (causing cramping), longitudinal muscle (increasing bowel transit time), and secretomotor neurons (making the stool hard and dry). ${ }^{34}$

Opioid-induced constipation is the new or worsening symptom of constipation in someone initiating or increasing opioid therapy and can be evaluated using patient-related outcome measures like the Bowel Function Index (BFI). ${ }^{35,36}$ The frequency of constipation among patients without cancer using chronic opioids has been reported as $41 \%,{ }^{37}$ while it ranges from $52-87 \%$ in patients with cancer (with the higher frequency amongst the terminally ill). ${ }^{38}$ It is more common in females and in those patients using 'strong' opioids like morphine and oxycodone, but less common in those using transdermal patches (eg fentanyl). ${ }^{39-42}$

Initial consideration can include opioid reduction (if the patient is pain free or other analgesic strategies can be used), to reduce the opioid burden on gut receptors. Opioid switching (eg to fentanyl or buprenorphine) and reduction of concomitant non-opioid constipating factors (like medications or electrolyte abnormalities) should also be considered. ${ }^{40,43}$

Non-pharmacological measures (like a high fibre diet) and oral laxatives have also traditionally been used; stimulants (eg senna, bisacodyl) and/or stool softeners (eg lactulose) are preferred. ${ }^{8}$ Rectal measures (eg enemas, suppositories) can also be trialled based upon findings of a digital rectal examination; however, there is little evidence base for this in the management of opioidinduced constipation. ${ }^{40}$

A new group of medications antagonise the peripheral $\mu$-opioid receptors (such as those in the gastrointestinal tract) without reversing the central analgesic effects of opioids, aiming to directly reverse the opioid's effect on the bowel. ${ }^{43}$ These peripheral opioid antagonist drugs should be considered in opioid-induced constipation, when traditional laxative therapy is ineffective. ${ }^{44}$

\section{Naloxegol}

Naloxegol is PEGylated naloxol. It is an oral peripherally acting selective $\mu$-opioid antagonist and is recommended by the National Institute for Health and Care Excellence (NICE) for relief of opioidinduced constipation that has not responded to treatment with standard laxatives. ${ }^{44}$ Overall, patients with non-laxative responsive opioid-induced constipation who received $25 \mathrm{mg}$ naloxegol (vs placebo) experienced more spontaneous bowel movements ( $44.4 \%$ vs $29.4 \%$ using intention to treat criteria). ${ }^{44-46}$ Naloxegol has not been studied in patients with cancer-related pain; however, the studies are believed to be generalisable to this population. ${ }^{44}$

\section{Methylnaltrexone}

Methylnaltrexone is derived from the opioid antagonist naltrexone and given via subcutaneous injection. It is approved for treating opioid-induced constipation in patients with advanced illness and ongoing constipation despite traditional laxatives ${ }^{8}$ and can be administered every other day for up to 4 months within this group. ${ }^{47}$ In a 2016 systematic review involving six RCTs (1239 patients), patients receiving methylnaltrexone (vs placebo) were more likely to have a spontaneous bowel movement within 4 hours (risk 0.385 vs 0.267 placebo, $p<0.0001$ ). ${ }^{48}$ The review considered trials with a mix 
of dosing regimens (most commonly $0.15 \mathrm{mg} / \mathrm{kg}$ alternate days, 0.3 $\mathrm{mg} / \mathrm{kg}$ daily, or $12 \mathrm{mg} /$ day subcutaneously).

\section{Oxycodone/naloxone}

This oral formulation contains a fixed 2:1 ratio of prolongedreleased oxycodone and the opioid antagonist naloxone (which has a high affinity for $\mu$-receptors and minimal systemic availability due to extensive first pass metabolism)..$^{49}$ The combination is only recommended up to doses of $160 \mathrm{mg}$ oxycodone/day ( $80 \mathrm{mg}$ naloxone), though supplemental prolonged release oxycodone can be used. ${ }^{49} \mathrm{~A}$ systematic review including four RCTs (using a combination of oxycodone/naloxone combination and oral naloxone added to existing opioid) reduced constipation compared to placebo. ${ }^{50}$

> Practice point: Treat opioid-related constipation by using the lowest dose of the least constipating opioid that controls pain. Use traditional non-pharmacological measures and laxatives first and consider peripherally acting $\mu$-opioid receptor antagonists when opioid-related constipation remains problematic despite laxative use.

\section{Upper respiratory secretions}

Noisy upper respiratory tract secretion accumulation (also referred to as 'death rattle') occurs in $23-92 \%$ of patients in the last hours to days of life. ${ }^{51}$ It is thought to be caused by salivary secretions within the hypopharynx. ${ }^{8}$

There is no evidence that respiratory secretions are associated with respiratory distress; ${ }^{52}$ it can however be very distressing for some family members and staff. ${ }^{53,54}$ To help alleviate this distress, it is often treated with antimuscarinic drugs (like hyoscine butylbromide or glycopyrronium) to reduce secretions. ${ }^{8}$ Any medical therapy should be combined with non-pharmacological measures ${ }^{55}$ and a comprehensive communication strategy. ${ }^{56}$ Healthcare staff should discuss with loved ones that breathing changes are an expected part of dying and that patients often remain comfortable.

\section{Anti-muscarinic drugs}

Systematic reviews (including a Cochrane review updated in 2012) have found no evidence of benefit over placebo for any pharmacological or non-pharmacological intervention to treat respiratory tract secretions in patients near to death. They therefore advise against the routine use of antimuscarinic drugs. ${ }^{57,58}$

This lack of benefit is thought to be partly because they are started after the secretions have built up when the patient has noisy breathing. Although antimuscarinic drugs can reduce production of new secretions, they do not decrease existing secretions. ${ }^{51}$

It is not currently possible to identify and target patients at higher risk of developing respiratory secretions, ${ }^{59}$ so selective prophylactic treatment also cannot be recommended. Because most patients with secretions have a reduced consciousness level, typical side effects of antimuscarinic treatments (like dry mouth, constipation and urinary retention) are seldom reported, but may cause discomfort or distress in patients unable to convey this. ${ }^{51}$

> Practice point: There is no evidence that antimuscarininc agents are of benefit in treating respiratory secretions in patients
Box 1. Recent pharmacological updates in palliative care

Oxygen can be trialled for symptomatic benefit in hypoxic patients who are breathless $\left(\mathrm{O}_{2}\right.$ saturation $\left.\leq 92 \%\right)$.

Systemic opioids ( $<30 \mathrm{mg}$ oral morphine equivalent/day) are a safe and effective treatment for breathlessness in advanced COPD.

Benzodiazepines could be considered as a second- or third-line agent in treating refractory breathlessness.

Antipsychotic medications should be reserved for treating severe and distressing delirium.

Somatostatin analogues have limited evidence to support their efficacy in treating vomiting in malignant bowel obstruction.

Naloxegol, methylnaltrexone and oxycodone/naloxone are all effective second-line treatments for opioid-induced constipation.

There is insufficient evidence to support the benefit of antimuscarinic drugs in treating respiratory tract secretions at the end of life. When these drugs are used, physicians should monitor for efficacy and adverse effects, and combine this with a communication strategy.

near to death. In cases where clinicians choose to use these agents, they should be combined with a careful communication strategy with the patient's family. Physicians should remain vigilant in their frequent assessment for efficacy and side effects.

\section{Conclusion}

Many reviews and trials discussed within this article found no evidence of benefit to the various pharmacological therapies. Although more and larger randomised controlled trials are still needed to guide treatment decisions, many recent findings mentioned here are already influencing clinical practice. Clinicians should continue to use a holistic approach to weigh up the individual risks and benefits of any proposed treatment on a caseby-case basis.

> Symptom management should begin with assessment of causes for the symptoms and reversing them where possible.

> Communication with patients and their families can help make symptoms less distressing (eg respiratory secretions in patients near end of life).

> Effective non-pharmacological treatments should often be trialled before or together with pharmacological therapy.

A summary of the recent pharmacological updates in palliative care reviewed in this article is shown in Box 1 .

\section{References}

1 Wood H, Dickman A, Star A, Boland JW. Updates in palliative care - overview and recent advancements in the pharmacological management of cancer pain. Clin Med 2018;18:17-22.

2 Parshall MB, Schwartzstein RM, Adams L et al. An official American Thoracic Society statement: update on the mechanisms, assessment, and management of dyspnea. Am J Respir Crit Care Med 2012;185:435-52. 
3 Ekstrom MP, Abernethy AP, Currow DC. The management of chronic breathlessness in patients with advanced and terminal illness. BMJ 2015;349:g7617.

4 Hardinge M, Suntharalingam J, Wilkinson T et al. Guideline update: The British Thoracic Society Guidelines on home oxygen use in adults. Thorax 2015:70:589-91.

5 Ekstrom M, Ahmadi Z, Bornefalk-Hermansson A et al. Oxygen for breathlessness in patients with chronic obstructive pulmonary disease who do not qualify for home oxygen therapy. Cochrane Database Syst Rev 2016;11:CD006429.

6 Hardinge M, Annandale J, Bourne S et al. British Thoracic Society guidelines for home oxygen use in adults. Thorax 2015;70(Suppl 1):i1-43.

7 Campbell ML, Yarandi H, Dove-Medows E. Oxygen is nonbeneficial for most patients who are near death. J Pain Symptom Manage 2013:45:517-23.

8 Twycross RG, Wilcock A, Charlesworth S. Palliative Care Formulary (PCF5). Nottingham: palliativedrugs.com Ltd, 2014.

9 Ekstrom MP, Bornefalk-Hermansson A, Abernethy AP, Currow DC. Safety of benzodiazepines and opioids in very severe respiratory disease: national prospective study. BMJ 2014;348:g445.

10 Barnes H, McDonald J, Smallwood N, Manser R. Opioids for the palliation of refractory breathlessness in adults with advanced disease and terminal illness. Cochrane Database Syst Rev 2016:3:CD011008

11 Hayen A, Wanigasekera V, Faull OK et al. Opioid suppression of conditioned anticipatory brain responses to breathlessness. Neuroimage 2017;150:383-94.

12 Beach D, Schwartzstein RM. The genesis of breathlessness - what do we understand? In: Booth S, Dudgeon D (eds), Dyspnoea in advanced disease: a guide to clinical management. New York: Oxford University Press, 2006:271.

13 Ekstrom M, Bajwah S, Bland JM et al. One evidence base; three stories: do opioids relieve chronic breathlessness? Thorax 2017, in press.

14 Brunton LL. Goodman \& Gilman's pharmacological basis of therapeutics. 12th edn. New York: McGraw-Hill Medical, 2011.

15 Simon ST, Higginson IJ, Booth S, Harding R, Bausewein C. Benzodiazepines for the relief of breathlessness in advanced malignant and non-malignant diseases in adults. Cochrane Database Syst Rev 2016;10:CD007354.

16 Barbetta C, Currow DC, Johnson MJ. Non-opioid medications for the relief of chronic breathlessness: current evidence. Expert Rev Respir Med 2017;11:333-41.

17 Hosie A, Davidson PM, Agar M, Sanderson CR, Phillips J. Delirium prevalence, incidence, and implications for screening in specialist palliative care inpatient settings: a systematic review. Palliat Med 2013;27:486-98

18 Grassi L, Caraceni A, Mitchell AJ et al. Management of delirium in palliative care: a review. Curr Psychiatry Rep 2015;17:550.

19 Todd OM, Teale EA. Delirium: a guide for the general physician. Clin Med 2017:17:48-53.

20 Hui D, Dev R, Bruera E. Neuroleptics in the management of delirium in patients with advanced cancer. Curr Opin Support Palliat Care 2016:10:316-23.

21 Agar MR, Lawlor PG, Quinn S et al. Efficacy of Oral Risperidone, Haloperidol, or Placebo for Symptoms of Delirium Among Patients in Palliative Care: A Randomized Clinical Trial. JAMA Intern Med 2017:177:34-42.

22 Tuca A, Guell E, Martinez-Losada E et al. Malignant bowel obstruction in advanced cancer patients: epidemiology, management, and factors influencing spontaneous resolution. Cancer Manag Res 2012:4:159-69.

23 Romeo M, de Los LGM, Cuadra Urteaga JL et al. Outcome prognostic factors in inoperable malignant bowel obstruction. Support Care Cancer 2016;24:4577-86.
24 Walsh D, Davis M, Ripamonti C et al. 2016 Updated MASCC/ ESMO consensus recommendations: Management of nausea and vomiting in advanced cancer. Support Care Cancer 2017;25:33340.

25 Zucchi E, Fornasarig M, Martella L et al. Decompressive percutaneous endoscopic gastrostomy in advanced cancer patients with smallbowel obstruction is feasible and effective: a large prospective study. Support Care Cancer 2016;24:2877-82.

26 Ripamonti C, Mercadante S, Groff L et al. Role of octreotide, scopolamine butylbromide, and hydration in symptom control of patients with inoperable bowel obstruction and nasogastric tubes: a prospective randomized trial. J Pain Symptom Manage 2000:19:23-34.

27 Clark K, Lam L, Currow D. Reducing gastric secretions-a role for histamine 2 antagonists or proton pump inhibitors in malignant bowel obstruction? Support Care Cancer 2009;17:1463-8.

28 Mercadante S, Porzio G. Octreotide for malignant bowel obstruction: twenty years after. Crit Rev Oncol Hematol 2012;83:388-92.

29 Obita GP, Boland EG, Currow DC, Johnson MJ, Boland JW. Somatostatin Analogues Compared With Placebo and Other Pharmacologic Agents in the Management of Symptoms of Inoperable Malignant Bowel Obstruction: A Systematic Review. J Pain Symptom Manage 2016;52:901-19.

30 Currow DC, Quinn S, Agar M et al. Double-blind, placebo-controlled, randomized trial of octreotide in malignant bowel obstruction. J Pain Symptom Manage 2015:49:814-21.

31 Mariani P, Blumberg J, Landau A et al. Symptomatic treatment with lanreotide microparticles in inoperable bowel obstruction resulting from peritoneal carcinomatosis: a randomized, double-blind, placebocontrolled phase III study. J Clin Oncol 2012;30:4337-43.

32 Mercadante S. Octreotide for malignant bowel obstruction: commentary on Currow et al. J Pain Symptom Manage 2015;49:813.

33 Mystakidou K, Tsilika E, Kalaidopoulou $\mathrm{O}$ et al. Comparison of octreotide administration vs conservative treatment in the management of inoperable bowel obstruction in patients with far advanced cancer: a randomized, double-blind, controlled clinical trial. Anticancer Res 2002:22:1187-92.

34 De Luca A, Coupar IM. Insights into opioid action in the intestinal tract. Pharmacol Ther 1996;69:103-15.

35 Gaertner J, Siemens W, Camilleri M et al. Definitions and outcome measures of clinical trials regarding opioid-induced constipation: a systematic review. J Clin Gastroenterol 2015;49:9-16.

36 Argoff CE, Brennan MJ, Camilleri M et al. Consensus Recommendations on Initiating Prescription Therapies for OpioidInduced Constipation. Pain Med 2015;16:2324-37.

37 Camilleri M. Opioid-induced constipation: challenges and therapeutic opportunities. Am J Gastroenterol 2011;106:835-42.

38 Ahmedzai SH, Boland JW. Constipation: opioid antagonists in people prescribed opioids. BMJ Clin Evid 2015;2015:2407.

39 Dorn S, Lembo A, Cremonini F. Opioid-induced bowel dysfunction: epidemiology, pathophysiology, diagnosis, and initial therapeutic approach. Am J Gastroenterol Suppl 2014;2:31-7.

40 Ahmedzai SH, Boland J. Constipation in people prescribed opioids. BMJ Clin Evid 2010;2010:2407.

41 Panchal SJ, Muller-Schwefe P, Wurzelmann JI. Opioid-induced bowel dysfunction: prevalence, pathophysiology and burden. Int ] Clin Pract 2007:61:1181-7.

42 Allan L, Richarz U, Simpson K, Slappendel R. Transdermal fentanyl versus sustained release oral morphine in strong-opioid naive patients with chronic low back pain. Spine (Phila Pa 1976) 2005;30:2484-90.

43 Boland JW, Boland EG. Pharmacological therapies for opioid induced constipation in adults with cancer. BMJ 2017;358:j3313.

44 (NICE) Technology appraisal guidance [TA345]. Naloxegol for treating opioid-induced constipation 2015. www.nice.org.uk/ guidance/ta345 [Accessed 20 April 2017]. 
45 Webster L, Chey WD, Tack J et al. Randomised clinical trial: the long-term safety and tolerability of naloxegol in patients with pain and opioid-induced constipation. Aliment Pharmacol Ther 2014:40:771-9.

46 Chey WD, Webster L, Sostek M et al. Naloxegol for opioid-induced constipation in patients with noncancer pain. N Engl J Med 2014;370:2387-96.

47 British Medical Association, Royal Pharmaceutical Society of Great Britain. BNF 71 London: BMA, Royal Pharmaceutical Company, 2016.

48 Mehta N, O'Connell K, Giambrone GP, Baqai A, Diwan S. Efficacy of methylnaltrexone for the treatment of opiod-induced constipation: a meta-analysis and systematic review. Postgrad Med 2016;128:282-9.

49 Electronic Medicines Compendium. Targinact $5 \mathrm{mg} / 2.5 \mathrm{mg}$, $10 \mathrm{mg} / 5 \mathrm{mg}, 20 \mathrm{mg} / 10 \mathrm{mg}$ and $40 \mathrm{mg} / 20 \mathrm{mg}$ prolonged-release tablets - Summary of Product Characteristics (SPC): Electronic Medicines Compendium; 2017. www.medicines.org.uk/emc/ medicine/22908 [Accessed 11 July 2017].

50 Ford AC, Brenner DM, Schoenfeld PS. Efficacy of pharmacological therapies for the treatment of opioid-induced constipation: systematic review and meta-analysis. Am J Gastroenterol 2013;108:156674; quiz 75.

51 Mercadante S. Death rattle: critical review and research agenda. Support Care Cancer 2014;22:571-5.

52 Campbell ML, Yarandi HN. Death rattle is not associated with patient respiratory distress: is pharmacologic treatment indicated? J Palliat Med 2013;16:1255-9.
53 Wee BL, Coleman PG, Hillier R, Holgate SH. The sound of death rattle I: are relatives distressed by hearing this sound? Palliat Med 2006:20:171-5.

54 Wee B, Coleman P, Hillier R, Holgate S. Death rattle: its impact on staff and volunteers in palliative care. Palliat Med 2008;22:173-6.

55 Cherny NI, Fallon M, Kaasa S, Portenoy RK, Currow DC (eds), Oxford textbook of palliative medicine, 5th edn. Oxford: Oxford University Press, 2015.

56 Shimizu Y, Miyashita M, Morita T et al. Care strategy for death rattle in terminally ill cancer patients and their family members: recommendations from a cross-sectional nationwide survey of bereaved family members' perceptions. J Pain Symptom Manage 2014:48:2-12.

57 Wee B, Hillier R. Interventions for noisy breathing in patients near to death. Cochrane Database Syst Rev 2008:CD005177.

58 Lokker ME, van Zuylen L, van der Rijt CC, van der Heide A Prevalence, impact, and treatment of death rattle: a systematic review. J Pain Symptom Manage 2014:47:105-22.

59 Likar R, Michenthaler MC, Traar R, Molnar M, Neuwersch S. Clinical factors influencing death rattle breathing in palliative care cancer patients: Non-interventional study. Z Gerontol Geriatr 2017;50:332-38.

Address for correspondence: Dr Angela Star, Macmillan Palliative Care Unit, Northern General Hospital, Sheffield Teaching Hospitals, Herries Road, Sheffield S5 7AU, UK. Email: angela.star@sth.nhs.uk 